\title{
Adverse effects of homeopathy, what do we know? A systematic review and meta-analysis of randomized controlled trials
}

Short Title: Systematic review of adverse effects in homeopathy

Trine Stub ${ }^{1}(\mathrm{PhD})$, Frauke Musial ${ }^{1}$ (Professor), Agnete A. Kristoffersen ${ }^{1}(\mathrm{PhD})$, Terje Alræk ${ }^{1}$ (Professor), Jianping Liu ${ }^{2}$ (Professor))

${ }^{1}$ The National Research Center in Complementary and Alternative Medicine (NAFKAM) Department of Community Medicine, Faculty of Health Science, UiT The Arctic University of Tromsø, 9037 Tromsø, Norway.

${ }^{2}$ Centre for Evidence-Based Chinese Medicine, Beijing University of Chinese Medicine, Beijing, China

Corresponding author: Trine Stub, Sykehusveien 23, UiT The Arctic University of Norway, 9037 Tromsø, Norway. Email: trine.stub@uit.no

Keywords: Adverse effects; adverse events; homeopathic aggravations; patient safety; systematic review; meta-analysis; risk assessment

\section{Highlights:}

- This review address the naive assumption that because of the generally diluted doses used homeopathy must be safe

- This review touches the neglected issue of the distinction between homeopathic aggravation, adverse reactions and adverse effects

- We found a similar risk for homeopathic treatment compared to controls such as placebo and conventional medicine.

Words: 5,187

\begin{abstract}
Objectives

Homeopathy is a popular treatment modality among patient, however there is sparse research about adverse effects of homeopathy. A concept unique for homeopathy, is homeopathic aggravation that is understood as a transient worsening of the patients' symptoms before an
\end{abstract}


expected improvement occurs. From a risk perspective it is vital that a distinction between homeopathic aggravations and adverse effects is established. There is a lack of systematic information on how frequent adverse effects and homeopathic aggravations are reported in studies. Therefore, a systematic review and meta-analysis were performed.

\section{Design and setting}

Sixteen electronic databases were searched for Randomized Controlled Trials (RCTs). The searches were limited from the year 1995 to January 2011. Forty-one RCTs, with a total of 6.055 participants were included. A subtotal of 39 studies was included in the additional metaanalysis.

\section{Results}

A total of 28 trials (68\%) reported adverse effects and five trials (12\%) reported homeopathic aggravations. The meta-analysis (including six subgroup comparisons) demonstrated that no significant difference was found between homeopathy and control with OR 0.99, 95\% CI 0.86 to $1.14, \mathrm{I}^{2}=54 \%$. More than two third of the adverse effects were classified as grade 1 (68\%) and two third were classified as grade 2 (25\%) and grade $3(6 \%)$ according to the Common Terminology Criteria for Adverse Effects. Homeopathic aggravation was classified as grade 1 (98\%) and grade 3 (2\%), suggesting that homeopathic aggravations were reported to be less severe than adverse effects. The methodological quality according to a method recommended in the Cochrane handbook for RCTs, was high.

\section{Conclusion}

Adverse effects including the concept of homeopathic aggravations are commonly reported in trials. The meta-analysis demonstrated that the proportion of patients experiencing adverse effects to be similar for patients randomized to homeopathic treatment compared to patients randomized to placebo and conventional medicine.

\section{Introduction}

Homeopathy was established and developed in Germany by Samuel Hahnemann in the late $18^{\text {th }}$ century, and since then the theory and practice of homeopathy have developed outside the established health services. The action of homeopathic remedies is questioned as most remedies are diluted to such a high degree that there is only a theoretical probability that molecules of the original substance are present in the remedy (1-3). Accordingly, homeopathic remedies of high dilutions are pharmacologically inactive. On the other hand some 
homeopathic remedies are less diluted (D6 or D12), meaning that these remedies could be pharmacologically active. However, research suggests (4) that it is low direct risk connected to homeopathic remedies. The possible risk is therefore classified as indirect, related to other aspects of clinical context and practice. In medical science, risk can be divided into direct and indirect risk. Direct risk is related directly to the intervention itself, such as the medication or the homeopathic remedy. Indirect risk is related to the treatment setting, such as the practitioner and the caring context (5-7).

In the United States 2.3\% of the adult population used homeopathy in 2007, and 2.9 billion USD were spent on homeopathic remedies (8). The 12 month prevalence of those who have visited a homeopath in Europe has been found to vary between 2\% in Great Britain (9) to 15\% in Germany (10). A survey among older German adults revealed that 21\% used homeopathy for their complaints (11). In Scandinavian countries the prevalence of persons who use homeopathy fluctuates between $7 \%$ and $14 \%$ (12).

Being female, having higher education, suffering from health complaints and using conventional health care have all been associated with the use of Complementary and Alternative Medicine (CAM), including homeopathy (13-15). Uncontrolled studies of homeopathy document consistent and sustained patient satisfaction (15). Patients used homeopathy for chronic, physical problems, as well as emotional complaints (14-16). The most frequent diagnoses for which they seek homeopathy are allergic rhinitis in adult males, headache in adult females and atopic dermatitis in children (17). Homeopathy is one of the most common CAM therapies in cancer care in Europe, ranging from 11\% across cancer diagnoses (18) up to 19\% in breast cancer patients (19). Among younger cancer patients in Germany, 45\% reported that they have used homeopathic remedies during their illness (20). The majority of the patients used homeopathy with the aim to increase the body's ability to fight cancer or to improve physical or emotional well-being (19).

A concept specific to homeopathy is homeopathic aggravations, which is defined as "a temporary worsening of existing symptoms following the administration of a correctly chosen homeopathic remedy". This reaction is seen as a favourable response to the treatment and is expected to be followed by an improvement (2, 21-23). In 2003, Grabia and Ernst (24) published a systematic review to investigate how homeopathic aggravations was reported in RCTs. From a total of 25 trials, eight reported homeopathic aggravations and six reported adverse effects. The authors claimed that, for safety reasons, the concept should be reported in trials. 
A systematic review of case reports published in 2012 (25) found that, among the included 38 primary reports, 30 reported direct adverse effects from homeopathic remedies and eight were related to adverse effects caused by the substitution of conventional medicine with homeopathy. This review initiated a broad and controversial discussion about the safety of homeopathic treatment which has already been raised with regard to the risk of homeopathy related to practice by Dantas in 1999 (26). In particular, Tournier et al (27) highlighted the importance of differentiation between homeopathic care and clinical negligence. Together with poor reporting quality of the primary sources (i.e. of applied potencies of the remedy) this may lead to a misinterpretation of causality. Nevertheless this scientific episode highlights the need for some criteria or guidelines that enables to document common standards of homeopathic treatment.

So far, homeopathic aggravations have mostly been reported in an anecdotal way. In one case (28), a nine-month old baby girl was given several homeopathic remedies to treat atopic dermatitis. The child developed Bullous Pemphigoid (BP) during the treatment period and when the baby was finally admitted to the hospital, the condition was life threatening. This situation occurred because the homeopath misinterpreted the worsening of the symptoms as homeopathic aggravations and continued the treatment. In this case only spars information regarding the prescription of the homeopathic remedies was documented and the author stated that "no conclusion about the role of the homeopathy in the triggering of BP can be made”. However, Posadzki et al. in their review judged Mercury intoxication as a possible explanation of the adverse effect as judged by the author of the primary report (25).

This case illustrates the difficulty of judging the likelihood of homeopathic aggravations and adverse effects in homeopathy. Good data on a well-recognized, easily detectable adverse effects may be available from randomized clinical studies (RCTs) (29), and since limited knowledge of how adverse effects and homeopathic aggravations are reported in trials - A systematic review is needed.

\section{Aims}

The aims of this paper are to 1. Systematically investigate how homeopathic aggravations and adverse effects are reported in randomized controlled trials. 2. Classify adverse effects and homeopathic aggravations according to the Common Terminology Criteria for Adverse Effects (CTCAE) (30). 3. Perform a meta-analysis to evaluate the risk for patients using homeopathy (consultation and/or homeopathic remedies) compared to controls. 


\section{Terminology}

Not only is the homeopathic intervention itself a very complex treatment situation, which includes much more components than the remedy, there is, moreover, an astounding variety of definitions of harmful events available. This situation makes a thorough discussion of the terminology, which forms the basis of the systematic review and meta-analysis presented here, necessary.

The homeopathic intervention is a very elaborate treatment situation that consists of in-depth consultations often reaching beyond the topic of bodily complaints and involving psychological problems as well. In addition, lifestyle advice is generally included and a part of the consultation.

In terms of safety concerns, the homeopathic remedies themselves are mostly considered harmless (4). According to the current pharmacological model any potential harm related to remedies of high dilutions must be related to indirect risk (see table 1 for definitions of concepts), such as e.g. risk related to the setting effects, such as the practitioner $(5,31)$. According to current scientific knowledge, only remedies of low dilutions have a potential to induce direct risk, since they do contain substrate. Nonetheless, homeopathic treatment with ultra-molecular remedies has been proven to be clinically effective, but the mechanisms of effect remain unclear and under discussion. It has been speculated, that psychological mechanisms such as the placebo effect, potentially play a role (32)

As a consequence of this complex situation, a rather broad definition of risk, including both direct and indirect risk, maybe most appropriate in order to map the potential harm to patients related to the homeopathic treatment situation (33). This definition should encompass all potentially unwanted effects, without making assumptions about their mechanisms. In the light of the obvious shortcomings of the pharmacological model with regard to homeopathy, it is moreover, essential, that this definition is also able to cover incidents, that are most likely not related to a pharmacological effect.

In Norway, the National Norwegian Medicines Agency (34), uses the term adverse effect. In this definition, an adverse effect is understood as all diseases or unwanted and/or harmful reactions resulting from a medication or an intervention, regardless of their relation to the actual treatment. This definition is quite similar to how Edward and Aronson (35), define adverse effects, namely as a term that encompasses all unwanted effects. In this understanding 
of adverse effect, no assumption about mechanism is made and as such, ambiguity is minimized.

According to Edward and Aronson (35), the term adverse effect in the above described understanding must be distinguish from the term adverse events. They understand adverse event as an adverse outcome that occurs while a patient is taking a drug, thus, there is a strong temporal association to the drug, but the harmful event must not necessarily be associated with it. Their definition is similar to the definition of adverse events used by the European Medicines Agency (36). There, adverse events are defined as "any untoward medical occurrence in a patient or clinical trial subject administered a medical product”. But here as well, these events do not necessarily have a causal relationship with the treatment. At the same time, the European Medicines Agency defines adverse effects as a response to a medicinal product which is noxious and unintended (36). In conclusion, the European Medicines Agency as well as the National Norwegian Medicines Agency have a common understanding of the term adverse effect.

To complicate the situation even more, the term adverse reactions is often used instead of adverse effects and both are often used interchangeable. However, an adverse effect is generally identified as being linked with the drug, whereas an adverse reaction is directly linked to the patient $(35,36)$.

Thus, even though it seems that there is a common intuitive understanding of what a harmful event related to a treatment is, it seems to be challenging to find a common terminology of terms to describe and define it. This confusing situation is most illustrative demonstrated by the fact, that even the current glossary of the CONSORT statement lacks a clear definition of adverse event and that a definition is still pending. http://www.consort-

statement.org/resources/glossary. Several attempts have been made to facilitate the reporting of harm related issues and a checklist for such reports has been developed (37). As a conclusion, the authors are well aware that the decision of which definition to choose, is to a large extend a matter of choice and other choices are well possible and reasonable.

The National Research Center for Complementary and Alternative Medicine (NAFKAM) in Norway is a governmentally funded national agency, organized as part of the Department of Community Medicine at the Arctic University of Norway. One major goal related to the implementation of NAFKAM and thus a part of NAFKAMs assignment is to ensure and frame the safe use of complementary medicine for the Norwegian citizens. The systematic 
review presented here is part of this assignment. It seem reasonable that NAFKAM utilizes a risk definition, which is in line the National Norwegian Medicines Agency(33), The Term "adverse effect” as it is understood in this definition includes more sources of risk than merely those related to the drugs and thus covers a sufficiently broad spectrum of potential risks. It is therefore also suitable for the complex treatments situation in complementary medicine in general and thus for homeopathy as a special case. Thus, we will use this term and understanding of harm for this review, being well aware, that this represents a conscious choice, rather than a generally accepted universal definition.

Moreover, we are aware, that the translation of the risk concept of homeopathic aggravation into a conventional medical terminology is challenging and may reflect a compromise, nonetheless a definition is needed in order to describe and document the potential risk related to homeopathy in all its facets. Homeopathic aggravation is a reaction to homeopathy which is a complex treatment regimen. Hence, a concept that includes both direct and indirect risk in order to categorize homeopathic aggravation into a conventional term is needed. We have therefore chosen to categorize homeopathic aggravation as a special kind of adverse effects in this review.

Hanemann stated in the Organon der Heilkunst $\S 161$ ”.... the so-called homeopathic aggravation, or rather the primary action of the homeopathic medicine that seems to increase somewhat the symptoms of the original disease, to the first or few hours, this is certainly true with respect to diseases of a more acute character and of recent origin: but where medicines of long action have to combat a malady of considerable or very long lasting...... Such increase of the original symptoms of a chronic disease can appear only at the end of treatment when the cure is almost quite finished.” Consequently, temporary and short time aggravations may be observed and reported in RCTs. However, longer lasting homeopathic aggravations are rather unlikely to be observed in clinical trials.

As a final caveat, we would like to pay attention to the fact that the only available information on adverse effects and homeopathic aggravations for this review was based on the information provided by the authors of the included trials.

Therefore, the results presented here are based on the following definitions:

- Adverse effects

- homeopathic aggravations 
Table 1: Definitions of harm concepts

\begin{tabular}{|c|c|c|}
\hline Terminology & Definition & References \\
\hline Risk & $\begin{array}{l}\text { A compound measure of the probability of an event, and } \\
\text { the magnitude and impact of its potentially negative } \\
\text { outcome of that event. }\end{array}$ & (38),(35) \\
\hline Indirect risk & $\begin{array}{l}\text { Risk related to the setting effects, such as the practitioner } \\
\text { rather than to the medicine. For example, a practitioner with } \\
\text { limited medical and homeopathic skills may overlook } \\
\text { serious symptoms and thereby cause a delay in necessary } \\
\text { conventional treatment. }\end{array}$ & $(6),(33)$ \\
\hline Direct risk & $\begin{array}{l}\text { Risk related to the intervention, e.g., harm caused by } \\
\text { pharmacological products, medical treatments and } \\
\text { procedures }\end{array}$ & (5), (6) \\
\hline $\begin{array}{l}\text { Homeopathic } \\
\text { aggravations } \\
\text { (direct and indirect } \\
\text { risk) }\end{array}$ & $\begin{array}{l}\text { A temporary worsening of existing symptoms following the } \\
\text { administration of a correctly chosen homeopathic } \\
\text { prescription, which is expected to be followed by an } \\
\text { improvement. }\end{array}$ & (23), (22) \\
\hline $\begin{array}{l}\text { Adverse effects } \\
\text { (direct and indirect } \\
\text { risk) }\end{array}$ & $\begin{array}{l}\text { All diseases or unwanted and/or harmful reactions resulting } \\
\text { from a medication or an intervention, regardless of their } \\
\text { relation to the actual treatment. }\end{array}$ & (34),(35) \\
\hline $\begin{array}{l}\text { Adverse reactions } \\
\text { (direct and indirect } \\
\text { risk) }\end{array}$ & $\begin{array}{l}\text { Present when the right drug was administered for the } \\
\text { correct indication, in the proper dose, by the right route, yet } \\
\text { still the patient develops an unwanted symptom, suffers } \\
\text { unexpectedly, and is exposed to unpreventable harm. } \\
\text { Adverse reactions may also result from some diagnostic } \\
\text { tests, therapeutic interventions or devices. }\end{array}$ & $(38),(39)$ \\
\hline $\begin{array}{l}\text { Adverse drug } \\
\text { reactions } \\
\text { (direct risk) }\end{array}$ & $\begin{array}{l}\text { An appreciably harmful or unpleasant reaction, resulting } \\
\text { from an intervention related to the use of a medicinal } \\
\text { product. The reaction predicts hazards regarding future } \\
\text { administration and warrant prevention or specific treatment, } \\
\text { or alteration of the dosage regimen, or withdrawal of the } \\
\text { product. }\end{array}$ & $(35,40)$ \\
\hline
\end{tabular}

\section{Methods}

\section{Searches}

The focus question was:

\section{Is homeopathy associated with adverse effects and/or homeopathic aggravations?}

The PICO format was used when searching for relevant articles, which included the following four parts:

Population: Patients using homeopathy, physicians and homeopaths who reported adverse effects and homeopathic aggravations in the included studies 
Intervention: Homeopathy, including everything a homeopath does in the consultation, such as a diagnostic in-depth interview, prescription of remedies, and life-style advice

Comparison: Placebo, conventional medicine, usual care, waiting lists, other complementary and alternative treatments (including herbs)

Outcome: Adverse effects, adverse events, adverse reactions, tolerability, side effects (or other safety terminology) and homeopathic aggravations

The following electronic databases were searched: AMED, Cinahl, Cochrane Central Register for Controlled Trial (Central) in the Cochrane library, Embase, Medline, PsycINFO, PubMed, Datadiwan, GIRI, HomBRex, Hom-Inform, CAM Quest, CAMbase, Theme eJournals and Karger. A manual search was performed in complementary medicine journals, collections of publications from experts in homeopathy and homeopathic philosophy books. In order to find additional studies not found by electronic or manual searches, the reference lists of publications were also checked.

Search Methods: Depending on the database, various combinations of MESH terms and keywords were used. These MESH terms were used: Homeopathy/Materia Medica/Risk Management/Drug tolerance. These keywords were used:

Homeopathy/homoeopathy/homeopathic/homoeopathic side effect*, safety, adverse effect*, adverse events*, homeopathic aggravation*. The filters were clinical trials, RCTs, high specificity, any human conditions of humans, English and German. As the meta-analysis by Linde et al (41) included studies up to 1995, the searches were limited to the time period from January 1992 to January 2011.

The first author, T.S, performed the searches, read the articles, and extracted the data, while T.A. was consulted in cases of doubt. [The Cochrane Library (searches from 2002-2011) and the PubMed (searches from 2002-1992) search strings are attached in the appendix].

The inclusion comprised randomized, therapeutic trials that were double blinded. The trials excluded had no registration of homeopathic aggravations or adverse effects. Moreover, all drug proving trials, homeopathic pathogenic trials and duplicated publications were excluded.

\section{Methodological assessment of the included RCTs}

In this present study, the methodological quality of the RCTs was assessed using the criteria in the Cochrane Reviewers' Handbook (42). The following criteria were included in the 
assessment: Participants, dropouts, power calculation, intention-to-treat analysis, method (allocation concealment and blinding), intervention, duration of treatment, main finding, and funding (table 2). The trials were rated as follows:

A was used to indicate an RCT with a high level of quality in which all the criteria were met. Adequate measures to conceal allocation were made. The central randomization was either serial numbered, opaque, sealed envelopes or other descriptions that contained convincing elements of concealment. Hence, low risk of bias.

B was used when the authors did not report allocation concealment at all, or reported an approach that did not fit one of the categories in A. Hence, moderate risk of bias.

C was used when the method of allocation was not concealed, such as alternation methods or the use of case record numbers. Such trials were excluded because of high risk of bias.

Total number and classification of adverse effects and homeopathic aggravations Studies were extracted for data on adverse effects and homeopathic aggravations according to the following criteria: The total number of adverse effects, number of patients experiencing adverse effects, the total number of homeopathic aggravations and the total number of patients experiencing aggravations, and the CTCAE grading of the symptoms. When summarizing the data, the total number of adverse effects and homeopathic aggravations were counted, regardless of the number of participants who experienced them. This means that one patient may experience more than one adverse effect. Adverse effects and homeopathic aggravations were recorded as reported and stated in the included trials. This means that the CTCAE grading was entirely dependent on the information provided in the articles.

In order to evaluate the harmful events according to severity, the CTCAE grading system was chosen (30).The CTCAE system grades adverse effects from 1 to 5, where 1 is mild, 2 is moderate, 3 is severe or medically significant, 4 is life threatening, and 5 is lethal. When reporting the grading of adverse effects, we reported the harmful events without the number of patients experiencing the events.

The CTCAE grading system was also applied for homeopathic aggravations. The reason was that the grading system relates to new or worsening symptoms, which means that the cause of the new or worsening symptoms is irrelevant for the grading. Three researchers (TA, AK, TS) categorized and graded the data. When disagreements occurred, the events were discussed until 
consensus was reached. TS is a certified homeopath and acupuncturist, and the TA is a certified acupuncturist in Norway.

\section{Meta- analyses}

For the calculation of the meta-analysis, the study populations were divided in patients experiencing adverse effects vs. patients not experiencing adverse effects in both homeopathy and control groups. If the studies were homogenous regarding the study design, participants, interventions, control and outcome measures, they were combined in a meta-analysis. Heterogeneity was defined as being significant, if $\mathrm{P}<0.10$.

Based on the total number of participants randomized to the treatment or control group, odds ratios and 95\% confidence intervals were calculated from the number of patients who experienced adverse effects in each group. In 15 studies with no adverse effects in one or both groups, a continuity correction of 0.5 was added to arrive at a valid approximation of an odds ratio according to the current recommendations on analysing adverse effect data (43). To perform a meta-analysis, data were entered directly from the data sheets into Review Manager 5 computer program (44).

\section{Results}

\section{Outcome of the literature searches}

A total of 1,129 articles with RCTs were identified. They were initially examined on the basis of titles and abstracts, and 1,079 were excluded from further examination for the following reasons: Seventy-five articles did not record adverse effects or homeopathic aggravations, 44 described homeopathic proving trials, 324 were irrelevant (according to the criteria), 439 were multiple article registrations in databases, 62 were written in other languages than English and German and 135 were CAM studies other than homeopathy. Seven articles were included after searching German databases. After a closer examination of the 57 identified studies (4547) (48-51) (52-102), 16 were excluded (table 1) (46-48, 89-102). A total of 41 RCTs (48-88) with 6,055 subjects were included in this review.

Figure1. Flow chart of the randomized controlled trials

The control intervention was a placebo in most of the RCTs $(n=31)(48-51,53,55-57,60-71,73,74$, $76,78-83,87,88,103)$. Further, placebo and conventional medicine in one trial $(n=1)(86)$, herbal medicine (Gingo biloba) in one trial ( $n=1)(59)$, usual care in one trial $(n=1)(72)$ and conventional medicine in five trials $(\mathrm{n}=5)(75,82,84,85,87)$. Any human condition of humans and any homeopathic remedy were considered. 
Table 2: Excluded studies

\section{Methodological quality of the RCTs}

A total of 32 trials (78\%) were rated as $\mathbf{A}$, demonstrating that the methodological quality in these trials was of high quality with low risk of bias. Nine trials (22\%) were rated as $\mathbf{B}(48,50$, $53,59,64,67,69,73,75)$, demonstrating average quality and medium risk of bias. A total of 22 trials (54\%) reported both sample size calculations and intention to treat analyses. Eight trials (20\%) did not report sample size calculations or intention to treat analyses (53, 57, 60, 61, 64, 67, 68 , 73). Four of these studies also had a methodological quality of $\mathbf{B}$ (medium quality) $(53,64,67,73)$. Based on this evaluation we concluded that the methodological quality of the majority of these trials was high. Key data of these studies are summarized in table 3 . The column Participants refers to the number of participants randomized to either the treatment or control group. Dropout refers to participants in the treatment and control group who left the study. Therefore, participants who completed the study can be calculated as follows, e.g., Aabel 2000: $(n=37)-(n=3)=(n=34)$ in the treatment group and $(n=33)-(n=1)=(n=32)$ in the control group.

Table 3: Assessment of the methodological quality of the randomized controlled trials

\section{Adverse effects}

From a total of 41 RCTs, 28 trials (68\%) reported adverse effects. A total of 491 participants experienced 690 adverse effects, 426 in the treatment groups and 264 in the control groups. Twelve trials (29\%) reported no cases of adverse effects. The adverse effects were mostly categorized as gastro-intestinal disorders, headache/dizziness or dermatitis. Sixty-eight percent $(n=466)$ were characterized as CTCAE grades $1,25 \%$ as grade $2(n=174), 6 \%$ as grade $3(n=39), 0,4 \%$ as grade $4(n=3)$ and $0,2 \%$ as grade $5(n=2)$. The adverse effects categorized as grade 4 and 5 were not related to study medication. Key data of adverse effects are summarized in table 4 .

The adverse effects were patients or physician reported and the harmful events were causality assessed in three trials $(55,56,70)$. There was an inconsistent use of referring measures of adverse effects. Twenty-seven trials $(54-56,59,61,62,64,65,70-73,75-78,80-86,88,91)$ used the terminology adverse effects or adverse events. These trials assessed the symptoms as mild/moderate or severe, or serious or non-serious. A three or four point tolerability scale was used in six trials $(49,50,59,84,85,88)$. Adverse effects were descriptively reported in five trials 
$(49,51,60,78,79)$. Four trials used the term adverse drug reactions $(66-68,75)$, two trials applied side effects $(63,69)$, and one trial used unexpected effects $(58)$.

\section{Homeopathic aggravations}

Five RCTs $(12 \%)(54,65,79,80,86)$ reported homeopathic aggravations four of these also reported adverse effects. One hundred and seven participants experienced a total of 158 homeopathic aggravations, 91 in the treatment groups and 67 in the control groups. The remaining 36 RCTs (88\%) reported no cases of homeopathic aggravations. Homeopathic aggravations were patient and physician reported, and the studies did not report whether the patients had been informed about the possibility of experience such events. Homeopathic aggravations were reported as worsening of the patients' symptoms, such as exacerbation of allergy, asthma, eczema, headache and hot flushes. Ninety-eight present was classified as CTCAE grade1 $(n=171)$ and $2 \%$ was classified as grade $3(n=4)$ (severe asthma attacks). Nonevents were classified as grade 2, 4, and 5.

Two trials classified homeopathic aggravations as adverse effects (80, 86). One study (52) reported these data descriptively, another study (11) classified them as adverse reactions, and one trial(104) classified worsening of symptoms as homeopathic aggravations. Both complex and single remedies of low and high dilutions were associated with reported adverse effects or homeopathic aggravations. Key data of homeopathic aggravations are summarized in table 4.

Table 4: and

\section{Meta-Analyses}

Adverse effects data from 39 RCTs were included in the meta-analysis with a total of 5.902 subjects (figure 2).

\section{Homeopathy versus overall control}

An overall comparison was made between homeopathy and control. Thirty-nine trials (5.902 participants) made this comparison and no significant difference was found between homeopathy and control (426/2947 versus 264/2955), with OR 0.99, 95\% CI 0.86 to 1.14 , I² = $54 \%$.

Different subgroup meta-analyses according to the categories of controls were performed and presented below.

\section{Homeopathy versus placebo}


A comparison was made between homeopathy and placebo. Thirty-one trials (4.836 participants) made this comparison and no significant difference was found between homeopathy and placebo ( $n=220 / 2436$ versus $n=157 / 2400)$, with OR $1.03,95 \%$ CI 0.89 to $1.20, \mathrm{I}^{2}=49 \%$.

\section{Homeopathy versus conventional medicine}

There was no significant difference between homeopathy and conventional medicine in a meta-analysis of five trials (43/355 versus $71 / 401$ ), with OR $0.82,95 \%$ CI 0.56 to $0.1 .21, \mathrm{I}^{2}=$ $67 \%$.

\section{Homeopathy versus herbs}

A comparison was made between homeopathy and herbal medicine. One trial (170 participants) made this comparison, and no significant difference was found between the groups (OR 0.72, 95\% CI 0.25 to 2.07, $P=0.54)$.

\section{Homeopathy versus usual care}

A comparison was made between homeopathy and usual care. One trial (47 participants) made this comparison and reported the same number of adverse effects in the homeopathy as in the usual care group (1//23 versus $1 / 24)$, with OR 1.02 , 95\% CI 0.30 to $3.51, P=0.97$.

\section{Homeopathy versus conventional medicine and placebo}

There was no significant difference between homeopathy and conventional medicine and placebo in a meta-analysis of one trial (7/46 versus 5/47), with OR 1.20, 95\% CI 0.71 to 2.03, $P=0.50$.

One study, in which the numbers of adverse effects without stating the respective number of patients affected by the adverse effects, was excluded from the analyses (105). Another study (52), that reported only homeopathic aggravation was also excluded from the meta-analysis.

Figure 2: Forest plot for the randomized controlled trials, including sub-group analysis according to the category of controls.

In order to investigate whether there was a difference between studies of low and high potency homeopathy, we performed a One Way Anova test. We found that the mean number 
of adverse effects in studies ( $n=20$ ) with low potency (D4 toD30) was 8.5\%, compared to $15.5 \%$ in studies $(n=6)$ with high potency ( $D 200$ and higher) $(\mathrm{p}=0.181)$.

\section{Discussion}

In this present review we found that adverse effects were reported in $68 \%$ of the RCTs, More than two third of these events was classified as CTCAE grade 1 (minor) and one third as grade 2 and 3 (moderate and severe/significant). The meta-analysis demonstrated the proportion of patients experiencing adverse effects to be similar for patients randomized to homeopathic treatment compared to patients randomized to control such as placebo and conventional medicine.

The CTCAE grading of adverse effects and homeopathic aggravations was solely based on the information provided in the articles. This grading must, therefore, be interpreted with caution. As such, the grading applied here should be understood as merely an approximation to a CTCAE grading.

Studies of effect require as a general rule randomized controlled trials. Adverse effects, however, may also be effectively investigated in non-randomized studies (106). Papanikolaou (107) compared the risks of 13 major harms due to medical interventions using data from both randomized controlled trials and observational studies. The results suggested that, if a nonrandomized study finds harm, changes are that a randomized study would find even greater harm in terms of the magnitude of absolute risk. The authors concluded that contrary to current belief, non-randomized studies were often more conservative in their estimates of risk compared to randomized trials. Moreover, rare adverse effects or long-term adverse effects are rather unlikely to be observed in clinical trials, and a thorough investigation may require the inclusion of cohort studies (42). Our study team have therefore in addition to the study presented here, also conducted a systematic review and meta-analysis of observational studies that will be published later.

A limiting factor in all meta-analyses is heterogeneity of included studies. Being aware that heterogeneity might be underestimated in a fixed effect model, and the current discussion on applying fixed or random effect models in meta-analyses of binary adverse data (108), we decided to perform a simple random effect model. This model is also recommended in metaanalysis of rare binary adverse effect data (43). According to the argumentation of Friedrich et al. (109) we decided to include studies with zero-cell counts because the exclusion of such trials enhances the "risk of inflating the magnitude of the pooled treatment effect". By using a 
continuity correction of 0.5 for studies with zero-cell counts, odds ratio can still be estimated and summed up with standard meta-analysis methods. The inclusion of zero event studies is particularly important in cases of adverse effects as applying the standard continuity correction leads to a conservative, but error free, approximation of the risk of adverse effects (108). Moreover, the sample sizes of such trials contribute to the total effect size and make this more valid. On the other hand, this present review investigating adverse effects, so whether the pattern of adverse effects are homogeneous across studies should be of no concern, given they were for different conditions and involving different treatments, one would expect heterogeneity.

The studies using high potency homeopathy had twice as many adverse effects reported than studies using low potency, however not at a significant level. We believe that this result is due to low number of studies included in the analysis. The reason was that the name and potency of the homeopathic remedies administrated to study participants were not reported in several trials (e.g. individualized homeopathy).

To address the question about publication bias we did a funnel plot. This demonstrated the absence of publication bias in this systematic review, hence not shown in this present paper. However, the topic in this review was not treatment effect, but the frequency of adverse effects in the included trials.

Strong efforts have been made to retrieve all RCTs on the subject, but one cannot be absolutely certain that they have all been found. On the other hand, the additional searches in German databases, a country with a strong homeopathic research tradition, strengthen the possibility that the majority of the available studies have been included. This methodological approach may have minimized the possibility for selection bias in this systematic review.

A total of 62 ( $n=62)$ studies were excluded because they were in other languages, mainly Russian and French. Many researchers find that data from more than 40 studies in a systematic review may be difficult to handle and therefore not recommended (110). We believe that the studies excluded from this review should be included in a separate review.

An inconsistent use of safety terminology was found in the included trials. Harm data was reported by different concepts, such as adverse effects, adverse events, side effects and adverse drug reactions. The grading was measured on different scales (mild, moderate and severe or serious vs. non-serious). Moreover, homeopathic aggravations were classified as 
adverse effects and adverse reactions. This inconsistent use of terminology made it difficult to categorize and evaluate the data systematically. Hence, a consistent taxonomy is preferable and in line with WHO recommendations (111).

The adverse effects in this present review were found to be minor to moderate and transient events, which is in line with Dantas and Rampes (4). Grabia and Ernst (24) found in a systematic review of homeopathic aggravations in 25 placebo-controlled RCTs, 33 adverse effects in the placebo groups and 97 in the homeopathy groups. No grading of the adverse effects was given in the article.

It is possible that adverse effects have been under-reported. Many patients and homeopaths find it difficult to accept that homeopathy can cause adverse effects, since the treatment is "natural "and thereby considered to be safe. Moreover, many homeopaths believe that high diluted remedies does not cause adverse effects (112).

Grabia and Ernst (24) reported also that 40 cases of aggravation in the placebo groups and 63 cases in the homeopathy groups. The authors concluded that although the included RCTs mentioned the phenomenon of homeopathic aggravations, the evidence was not strong enough to provide support for the existence of aggravations. The frequency of homeopathic aggravations reported in the review from Grabia and Ernst, is in accordance with the findings from this present review. However, the frequency of reported homeopathic aggravations may be too low, since there is a lack of an adequate reporting system that include homeopathic aggravations.

\section{Conclusion}

Adverse effects including the concept of homeopathic aggravations are commonly reported in trials. The meta-analysis demonstrated that the proportion of patients experiencing adverse effects to be similar for patients randomized to homeopathic treatment compared to patients randomized to placebo and conventional medicine. The different harm terminology applied in the included studies and lack of standard reporting procedures made this work challenging and may bias this findings.

\section{Competing Interests}

The authors declare that they have no competing interests and that no financial interest exists. 


\section{Authors' contributions}

TS conceived the study, performed the searches and selected studies for inclusion and collected study data, assessed the studies for risk of bias (methodological assessment), developed the risk of bias table, prepared the data for the statistical analysis and drafted the manuscript. FM and AK developed the risk of bias table, prepared the data for the statistical analysis and reviewed the subsequent version of the manuscript. TA selected studies for inclusion and collected study data and reviewed the subsequent version of the manuscript. JL performed the statistical analysis (the forest plots) and prepared the data for the statistical analysis. All authors read and approved the final manuscript.

\section{Acknowledgements}

We want to thank Claudia Witt and Rainer Lüdtke for sharing and preparing data on homeopathic aggravations for us and Jane Ekelund, Åsa Sohlén and Kari Riddervold for technical support. We also want to thank The Norwegian Homeopathic Association for financial support.

\section{References}

1. Schabe W. Elementa Homoeopathica. Karlsruhe Engelhardt \& Bauer, Karlsruhe (Baden); 1960.

2. Swayne J. International dictionary of homeopathy. London: Churchill Livingstone; 2000.

3. Lockie A. Encyclopedia of Homeopathy. London: Dorling Kindersley Limited. A Penguin Company; 2005.

4. Dantas F, Rampes H. Do homeopathic medicines provoke adverse effects? A systematic review. $\mathrm{Br}$ Hom J. 2000;89:35-8.

5. Fisher P, Dantas F, Rampes H. The safety of homeopathic products J R Soc Med. 2002;95(9 ):474-6.

6. Ernst E. Intangible risks of complementary and alternative medicine. Journal of Clinical Oncology 2001;19(8):2365-6.

7. Stub T. Safety of Treatment Provided by Homeopaths - Homeopathic Aggravations, Adverse effects and Risk Assessment. [PhD thesis]. Troms $\varnothing$ : UiT The Arctic University of Norway, Troms $\varnothing 2013$.

8. Nahin RL, Stussmann BJ, Bloom B. Cost of Complementary and Alternative Medicine (CAM) and Frequency of Visits to CAM Practitioner: United States. Hyattsville: National Centres for Complementary and Alternative Medicine, Statistics NCfH; 200718.

9. Frass M, StrassI RP, Friehs H, Müllner M, Kundi M, Kaye AD. Use and Acceptance of Complementary and Alternative Medicine Among the General Population and medical Personnel: A Systematic review. The Ochsner Journal. 2012;12(1):45-56.

10. Haertel U, Volger E. [Use and acceptance of classical natural and alternative medicine in Germanyfindings of a representative population-based survey]. Forsch Komplementärmed Klass Naturheilkd. 2004;Dec;11(6):327-34.

11. Büssing A, Ostermann T, Heusser P, Mattiessen PF. Usage of alternative medical systems, acupuncture, homeopathy and anthroposophic medicine, by older German adults. Journal of Chinese Integrative Medicine. 2011;9(8):847-56.

12. Hansen B, Grimsgaard S, Launs $\varnothing$ L, Fønnebø V, Falkenberg T, Rasmussen K. Use of comlementary and alternative medicine in the Scandinavian countries. Scand J Prim Health Care. 2005;23:52-62.

13. Harris $P$, Rees $R$. The prevalence of complementary and alternative medicine use among the general population: a systematic review of the literature. Complementary Therapies in Medicine. 2000;8(2):88-96.

14. Jacobs J, Chapman EH, Crothers D. Patient Characteristics and Practice Patterns of Physicans Using Homeopathy. Arch Fam Med. 1998;7:537-9.

15. Anelli M, Scheepers L, Sermeus G, van Wassenhoven M. Homeopathy and health related Quality of Life: A survey in six European countries. Homeopathy. 2002;91:18 - 21. 
16. Pomposelli R, Andreni C, Costini G, Dedor B, Mariani M, Castellini M, et al. Opinions and self-reported health status of Italians seeking homeopathic treatment. Homeopathy. 2006;95:81-7.

17. Becker-Witt C, Lüdke R, Weishuhn TER, Willich SN. Diagnoses and Treatment in Homeopathic Medical Practice. Forsch Komplementärmed und Klass Naturheilkd 2004;11:98-103.

18. Molassiotis A, Fernandez-Ortega P, Pud D. Use of complementary and alternative medicine in cancer patients:a European survey. Ann Oncol. 2005;16(16):655-63.

19. Molassiotis A, Scott J, Kearney N, Pud D, Magri M, Selvekerova S. Complementary and alternative medicine use in breast cancer patients in Europe. Supportive care in Cancer. 2006;14(3):260-7.

20. Länger A, Edelhäuser F, Kameda G, Kaatsch P, Seifert G. Use of homeopathy in pediatric Oncology in Germany. Evidence-Based Complementary and Alternative Medicine. 2011;2011:1-7.

21. Paterakis S, Bachas I, Vithoulkas G. Statistical data on aggravation after the similimum. J Am Inst Homeopath. 1977;70(1):267-9.

22. Owen D. Principles and Practice of Homeopathy. The Therapeutic and Healing Process. Owen DD, editor. Southampton University: Churchill Livingstone Elsevier; 2007.

23. Hahneman S. Organon of Medicine (5th and 6th Edition). Translated by Dudgeon RE \& Boeriche W. 6th ed. New Delhi: B. Jain Publishers Pvt.Ltd; 2001.

24. Grabia S, Ernst E. Homeopathic aggravations: A systematic review of randomised, placebo-controlled clinical trials. Homeopathy. 2003;92:92-8.

25. Posadzki P, Alotaibi A, Ernst E. Adverse effects of homeopathy: A systematic review of published case reports and case series. Int J Clin Pract. 2012;Des;66(12):1178-88.

26. Dantas F. Reproting and investigating adverse effects of homeopathy. Br Hom J. 1999;88:99-100.

27. Tournier A, Roberts ER, Viksveen P. Adverse effects of homeopathy: a systematic review of published case reports and case series - comment by Tournier et al. Int J Clin Pract. 2013;67(4):388-89.

28. Kuenzli S, Grimaitre M, Krischer J, Saurat JH, Calza AM, Borradori L. Childhood Bullous Pemphigoid: Report of a Case with Life-Threatening Course During Homeopathy Treatment. Pediatric Dermatology. 2004;21(2):160-3.

29. Loke YK, Price D, Herxheimer A, The Cochrane Adverse Effects Methods Group. Systematic reviews of adverse effects: framework for a structured approach. BMC Medical Research Methodology 2007;7(32).

30. Trotti A, Colevas AD, Setser A, Rusch V, Jaques D, Budach V, et al. CTCAE v3.0: development of a comprehensive grading system for the adverse effects of cancer treatment. Seminars in Radiation Oncology. 2003;13(3):176-81.

31. Stub T, Alraek T, Salamonsen A. The Red flag! Risk assessment among medical homeopaths in Norway: A qualitative study. BMC Complement Altern Med. 2012;12(1):150.

32. Finniss DG, Kaptchuk T, Miller F, Benedetti F. Biological, clinical, and ethical advances of placebo effects. The Lancet. 2010;375(February):686-95.

33. Stub T, Salamonsen A, Kristoffersen A, Musial F. How to Handle Worsening of Condition during Treatment - Risk Assessment in Homeopathic Practice. Forschende Komplementärmedizin / Research in Complementary Medicine. 2015;22(1):30-5.

34. Statens legemiddelverk (Norwegian Medicines Agency). Bivirkningsrapporten 2011. Seksjon for legemiddelovervåkning. Oslo: Statens legemiddelverk, 2011.

35. Edwards IR, Aronson JK. Adverse drug reactions: definitions, diagnosis, and management. The Lancet. 2000;356(9237):1255-9.

36. Eupean Medicines Agency. Guideline on good pharmacovigilance practices (GVP), Annex I - Definitions (Rev 3). London: Eupean Medicines Agency, 2014.

37. Ioannidis JPA, Evans SJW, Gøtzsche PC, O'Neill RT, Altman DG, Schulz K, et al. Better Reporting of Harms in Randomized Trials: An Extension of the CONSORT Statement. Annals of Internal Medicine. 2004;141(10):781-8.

38. Runciman WB. Shared meanings: Preferred terms and definitions for safety and quality concepts. Med J Aust. 2006;184(10):41-3.

39. World Health Organization. The Importance of Pharmacovigilance. Safety Monitoring of Medical Products. Geneva: World Health Organization, 2002.

40. European Medicines Agency. ICH Topic E 6 (R1) Guideline for Good Clinical Practice. London: European Medicines Agency, 2002 Contract No.: E 6 (R1).

41. Linde K, Clausius N, Ramirez G, Melchart D, Eitel F, Hedges LV, et al. Are the clinical effects of homoeopathy placebo effects? A meta - analysis of placebo-controlled trials. The Lancet. 1997;350:834-43.

42. Higgins JPT. Cochrane Handbook for Systematic Reviews of Interventions 5.1.0. Green S, editor. Chichester U.K.: Wiley \& Sons, Ltd; Updated March 2011. 
43. Bhaumik DK, Amatya A, Normand SL, Greenhouse J, Kaizar E, Neelon B, et al. Meta-Analysis of Rare Binary Adverse Event Data. J Am Stat Assoc. 2012;Jun 1;107(498):555-67.

44. Review Manager (RevMan) [Computer program]. Version 5.3. Copenhagen: The Nordic Cochrane Centre, The Cochrane Collaboration. 2014.

45. Friese $\mathrm{KH}$, Kruse S, Luedtke R, Moeller $\mathrm{H}$. The homeopathic treatment of otitis media in childrencomparison with conventional therapy. International Journal of Clinica Pharmacology and Therapeutics 1997;37(7):296-301.

46. Strösser W, Weiser M. Patienten mit Gonarthrose gewinnen ihre Mobilität zurück, Homöopathikum im Doppelblind-Vergleich. BM. 2000;29(6):295-9.

47. Schirmer KP, Fritz M, Jäckel WH. Wirksamkeit von Formica rufa und Eigenblut -Injektionen bei Patienten mit ankylosierender Spondylitis:Eine doppelblinde, randomisierte studie. . Zeitschrift für Rheumatologie. 2000;59(5).

48. Beer AM, Heiliger F. Randomized, double-blind trial of caulophyllum d4 for induction of labor after premature rupture of the membranes at term. Geburtshilfe und Frauenheitkunde. 1999;59:431-5.

49. Bergmann J, Luft B, Boehmann S, Runnebaum B, Gerhard I. The efficacy of the complex medication Phyto-Hypophyson $L$ in female, hormone-related sterility. A randomized, placebo-controlled clinical doubleblind study [German]. Forschende Komplementärmedizin und Klassische Naturheilkunde. 2000;7:190-9.

50. Friese KH, DI Z. Homöopathie bei akuter Rhinosinusitis. HNO. 2007;Apr 555(4):271-7.

51. Diefenbach M, Schilken J, Steiner G, Becker HJ. Homeopathic therapy in respiratory tract diseases. Evaluation of a clinical study in 258 patients. Zeitschrift für Allgemeinmedizin. 1997;73:308-14.

52. Aabel S, Laerum E, Dølvik S, Djupesland P. Is homeopathic 'immunotherapy' effective? A double-blind, placebo-controlled trial with the isopathic remedy Betula 30c for patients with birch pollen allergy. British Homoeopathic journal. 2000;89(4):161-8.

53. Attena F, Toscano G, Agozzino E, Del Giudice N. A randomized trial in the prevention of influenza-like symptoms by homeopathic management. RevEpidémet Santé. 1995;43:380-2.

54. Brien S, Lachance L, Prescott P, McDermott C, Lewith G. Homeopathy has clinical benefits in rheumatoid arthritis patients that are attributable to the consultation process but not the homeopathic remedy: A randomized controlled clinical trial. Rheumatology. 2010.

55. Brinkhaus B, Wilkens JM, Lüdtke R, Hunger J, Witt CM, Willich SN. Homeopathic Arnica therapy in patients receiving knee surgery: Results of three randomised double-blind trials. Complementary Therapies in Medicine. 2006;14(4):237-46.

56. Cornu C, Joseph P, Gaillard S, Bauer C, Vedrinne C, Bissery A, et al. No effect of a homoeopathic combination of Arnica montana and Bryonia alba on bleeding, inflammation, and ischaemia after aortic valve surgery. British Journal of Clinical Pharmacology. 2010;69(2):136-42.

57. Frass M, Linkesch M, Banyai S, Resch G, Dielacher C, Löbl T, et al. Adjunctive homeopathic treatment in patients with severe sepsis: A randomized, double-blind, placebo-controlled trial in an intensive care unit. Homeopathy. 2005;94(2):75-80.

58. Friese K-H, Feuchter U, Lüdtke R, Moeller H. Results of a randomised prospective double-blind clinical trial on the homeopathic treatment of adenoid vegetations. European Journal of General Practice. $2001 ; 7(2): 48-54$.

59. Issing W, Klein P, Weiser M. The Homeopathic Preparation Vertigoheel $\hat{A}^{\circledR}$ Versus Ginkgo biloba in the Treatment of Vertigo in an Elderly Population: A Double-Blinded, Randomized, Controlled Clinical Trial. The Journal of Alternative and Complementary Medicine. 2005;11(1):155-60.

60. Jacobs J, Fernandez EA, Merizalde B, Avila-Montes GA, Crothers D. The use of homeopathic combination remedy for dengue fever symptoms: A pilot RCT in Honduras. Homeopathy. 2007;96(1):22-6.

61. Jacobs J, Herman P, Heron K, Olsen S, Vaughters L. Homeopathy for Menopausal Symptoms in Breast Cancer Survivors: A Preliminary Randomized Controlled Trial. The Journal of Alternative and Complementary Medicine. 2005;11(1):21-7.

62. Jacobs J, Springer D, Crothers D. Homeopathic treatment of acute otitis media in children: A preliminary randomized placebo-controlled trial. The Pediatric Infectious Disease Journal. 2001;20(2):177-83.

63. Jacobs J, Williams AL, Girard C, Njike VY, Katz D. Homeopathy for Attention-Deficit/Hyperactivity Disorder: A Pilot Randomized-Controlled Trial. The Journal of Alternative and Complementary Medicine. 2005;11(5):799-806.

64. Jeffrey SLA, Belcher HJCR. Use of Arnica to relieve pain after carpal-tunnel release surgery. Alternative therapies. 2002;8(2):66-8. 
65. Kim LS, Riedlinger J E, Baldwin CM, Hilli L, Khalsa SV, Messer SA, et al. Treatment of Seasonal Allergic Rhinitis Using Homeopathic Preparation of Common Allergens in the Southwest Region of the US: A Randomized, Controlled Clinical Trial. Ann Pharmacother. 2005;39(4):617-24.

66. Lewith GT, Watkins AD, Hyland ME, Shaw S, Broomfield JA, Dolan G, et al. Use of ultramolecular potencies of allergen to treat asthmatic people allergic to house dust mite: Double blind randomised controlled clinical trial. BMJ. 2002;324(7336):520.

67. Mousavi F, Mojaver YN, Asadzadeh M, Mirzazadeh M. Homeopathic treatment of minor aphthous ulcer: A randomized, placebo-controlled clinical trial. Homeopathy. 2009;98(3):137-41.

68. Naudé DF, Stephanie Couchman IM, Maharaj A. Chronic primary insomnia: Efficacy of homeopathic simillimum. Homeopathy. 2010;99(1):63-8.

69. Oberbaum M, Galoyan N, Lerner-Geva L, Singer SR, Grisaru S, Shashar D, et al. The effect of the homeopathic remedies Arnica montana and Bellis perennis on mild postpartum bleeding-A randomized, double-blind, placebo-controlled study-Preliminary results. Complementary Therapies in Medicine.

2005;13(2):87-90.

70. Oberbaum M, Yaniv I, Ben-Gal Y, Stein J, Ben-Zvi N, LS; F, et al. A randomized, controlled clinical trial of the homeopathic medication TRAUMEEL $s^{\circledR}$ in the treatment of chemotherapy-induced stomatitis in children undergoing stem cell transplantation. Cancer. 2001;92(3):684-90.

71. Paris A, Gonnet N, Chaussard C, Belon P, Rocourt F, Saragaglia D, et al. Effect of homeopathy on analgesic intake following knee ligament reconstruction: A phase III monocentre randomized placebo controlled study. British Journal of Clinical Pharmacology. 2008;65(2):180-7.

72. Relton C, Smith C, Raw J, Walters C, Adebajo AO, Thomas KJ, et al. Healthcare provided by a homeopath as an adjunct to usual care for Fibromyalgia (FMS): Results of a pilot Randomised Controlled Trial. Homeopathy. 2009;98(2):77-82.

73. Silk R, LeFante C. Safety of Zinc Gluconate Glycine ( Cold-Eeze) in a Geriatric Population: A Randomized, Placebo-Controlled, Double-Blind Trial. American Journal of Therapeutics. 2005;12:612-7.

74. Singer SR, Amit-Kohn M, Weiss S, Rosenblum J, Moaz G, Samuels N, et al. Traumeel S for pain relief following hallux valgus surgery: A randomized controlled trial. BMC Clinical Pharmacology. 2010;10(9):1-8.

75. Stam C, Bonnet MS, van Haselen RA. The efficacy and safety of a homeopathic gel in the treatment of acute low back pain: A multi-centre, randomised, double-blind comparative clinical trial. Brithish Homeopathic Journal. 2001;90:21-8.

76. Steinsbekk A, Bentzen N, Fønnebø V, Lewith G. Self treatment with one of three self selected, ultramolecular homeopathic medicines for the prevention of upper respiratory tract infections in children. A double-blind randomized placebo controlled trial. British Journal of Clinical Pharmacology. 2005;59(4):447-55. 77. Steinsbekk A, Fønneb $\varnothing$ V, Lewith G, Bentzen N. Homeopathic care for the prevention of upper respiratory tract infections in children: A pragmatic, randomised, controlled trial comparing individualised homeopathic care and waiting-list controls. Complementary Therapies in Medicine. 2005;13(4):231-8.

78. Stevinson C, Devaraj VS, Fountain-Barber A, Hawkins S, Ernst E. Homeopathic Arnica for prevention of pain and bruising: Randomized placebo-controlled trial in hand surgery. J R Soc Med. 2003;96(2):60-5.

79. Straumsheim P, Borchgrevink C, Mowinckel P, Kierulf H, Hafslund O. Homeopathic treatment of migraine: A double blind, placebo controlled trial of 68 patients. British Homoeopathic Journal. 2000;89(1):4-7.

80. Taylor MA, Lancaster T, Reilly D, Llewellyn-Jones RH, McSharry C, Aitchison TC, et al. Randomised controlled trial of homoeopathy versus placebo in perennial allergic rhinitis with overview of four trial series. BMJ. 2000;321(7259):471-6.

81. Thompson EA, Montgomery A, Douglas D, Reilly D. A Pilot, Randomized, Double-Blinded, PlaceboControlled Trial of Individualized Homeopathy for Symptoms of Estrogen Withdrawal in Breast-Cancer Survivors. The Journal of Alternative and Complementary Medicine. 2005;11(1):13-20.

82. van Haselen RA, Fisher PAG. A randomized controlled trial comparing topical piroxicam gel with a homeopathic gel in osteoarthritis of the knee. Rheumatology. 2000;39(7):714-9.

83. Vickers A, Fisher P, Smith C, Sheena W, Reers R. Homeopathic Arnica is ineffective for Muscle Soreness After Long-Distance Running: A Randomized Double-Blind, Placebo-Controlled Trial. The Clinical Journal of Pain. $1998 ; 14(3): 227-31$.

84. Weiser M. Homeopathy vs Conventional Treatment of Vertigo. Arch otolaryngol Head Nech Surg. 1998;124(Aug):879-85.

85. Weiser M, Gegenheimer LH, Klein P. A Randomized Equivalence Trial Comparing the Efficacy and Safety of Luffa comp.-Heel Nasal Spray with Cromolyn Sodium Spray in the Treatment of Seasonal Allergic Rhinitis. Forschende Komplementärmedizin und Klassische Naturheilkunde. 1999;6:142-8. 
86. White A, Slad P, Hunt C, Hart A, Ernst E. Individualised homeopathy as an adjunct in the treatment of childhood asthma: A randomised placebo controlled trial. Thorax. 2003;58(4):317-21.

87. Witt A, Kaufmann U, Bitschnau M, Tempfer C, Özbal A, Haytouglu E, et al. Monthly itraconazole versus classic homeopathy for the treatment of recurrent vulvovaginal candidiasis: A randomised trial. BJOG: An International Journal of Obstetrics \& Gynaecology. 2009;116(11):1499-505.

88. Zabolotnyi DI, Kneis KC, Richardson A, Rettenberger R, Heger M, Kaszkin-Bettag M, et al. Efficacy of a Complex Homeopathic Medication (Sinfrontal) in Patients with Acute Maxillary Sinusitis: A Prospective, Randomized, Double-Blind, Placebo-Controlled, Multicenter Clinical Trial. The Journal of Science and Healing. 2007;3(2):98-109.

89. Aabel S. No beneficial effects of isopathic prophylactic treatment for birch pollen allergy during a lowpollen season: a double-blind, placebo-controlled clinical trial of homeopathic Betula 30c. Brithish Homeopathic Journal. 2000;89:169-73.

90. Bell IR, Lewith DA, Brooks AJ, Schwartz GE, Lewis SE, Walsh BT, et al. Improved clinical status in fibromyalgia patients treated with individualized homeopathic remedies. Rheumatology. 2004;43:577-82.

91. Bell IR, Lewith DA, Brooks AJ, Schwartz GE, Lewis SE, Caspi O. Individual Differences in Response to Randomly Assigned Active Individualized Homeopathic and placebo Treatment in Fibromyalgia: Implications of a Double-Blined Optional Crossover Design. The Journal of Alternative and Complementary Medicine. 2004;10(2):269-83.

92. Bernstein S, Donsky H, Gulliver W, Hamilton D, Nobel S, Norman R. Treatment of Mild to Moderate psoriasis with Relieva, a Mahonia aquifolium Extract - A Double-Blind, Placebo-Controlled Study. American Journal of Therapeutics. 2006;13:121-6.

93. Ferrara P, Marrone G, Emmanuele V, Nicoletti A, Mastrangelo A, Tiberi E, et al. Homotoxicological remedies versus desmopressin versus placebo in the treatment of enuresis: A randomised, double-blind, controlled trial. Pediatric Nephrology. 2008;23(2):269-74.

94. Garrett B, Harrison PV, Stewart T, Porter I. A trial of homoeopathic treatment of leg ulcers. Journal of Dermatological Treatment. 1997;8(2):115-7.

95. Hill N, Stam C, van Haselen R. The efficacy of Prrrikweg gel in the treatment of insect bites: a doubleblind placebo-controlled clinical trial. Pharmacy World \& Science. 1996;18(1):35-41.

96. Jeaner M, Henry MF, Garcia A, Marichal B. Evaluation of 2LHERP in preventing recurrences of genital herpes. Brithish Homeopathic Journal. 2000;89:174-7.

97. Katz T, Fisher P, Katz A, Davidson J, Feder G. The feasibility of a randomised, placebo-controlled clinical trial of homeopathic treatment of depression in general practice. Homeopathy. 2005;94(3):145-52.

98. Mousavi F, Sherafati S, Nozad Mojaver Y. Ignatia in the treatment of oral lichen planus. Homeopathy. 2009;98(1):40-4.

99. Seeley BM, Denton AB, Ahn MS, Maas CS. Effect of Homeopathic Arnica montana on Bruising in Facelifts. Archives of Facial Plastic Surgery. 2006;8(1):54-9.

100. Tveiten D, Bruset S. Effect of Arnica D30 in marathon runners. Pooled results from two double-blind placebo controlled studies. Homeopathy. 2003;92(4):187-9.

101. Friese K, Kruse F, Ludtke R, Moller H. The homeopathic treatment of otitis media in children comparisons with conventional therapy. Int J Clin Pharmacol Ther. 1997;35:296 - 301.

102. Frass M, Linkesch M, Banyai S, Resch G, Dielacher C, Löbl T, et al. Adjunctive homeopathic treatment in patients with severe sepsis: A randomized, double-blind, placebo-controlled trial in an intensive care unit. Homeopathy. 2011;100(1-2):95-100.

103. Steinsbekk A, Fonnebo V, Lewith G, Bentzen N. Homeopathic care for the prevention of upper respiratory tract infections in children: A pragmatic, randomised, controlled trial comparing individualised homeopathic care and waiting-list controls. Complement Ther Med. 2005;13:231 - 8.

104. Thompson E, Barron S, Spence D. A preliminary audit investigating remedy reactions including adverse events in routine homeopathic practice. Homeopathy. 2004;93(4):203-9.

105. Brien S, Lachance L, Prescott P, McDermott C, Lewith G. Homeopathy has clinical benefits in rheumatoid arthritis patients that are attributable to the consultation process but not the homeopathic remedy: a randomized controlled clinical trial. Rheumatology (Oxford). 2011;50:1070 - 82.

106. Miettinen OS. The need for randomization in the study of intended effects. Stat Med. 1983;2(2):267-

71.

107. Papanikolaou PN, Christidi GD, loannidis JPD. Comparison of evidence on harms of medical interventions in randomized and nonrandomized studies. Canadian Medical Association Journal. 2006;174(5):635-41. 
108. Sweeting MJ, Sutton AJ, Lambert PC. What to add to nothing? Use and avoidance of continuity corrections in meta-analysis of sparse data Stat Med. 2004;May 15;23(9):1351-75.

109. Friedrich JO, Adhikari NK, Beyene J. Inclusion of zero total event trials in meta-analyses maintains analytic consistency and incorporates all available data. BMC Med Res Methodol. 2007;23:7-5.

110. Martinussen M, Araï D, Friborg O, Hagtvet KA, Handegård BH, Jacobsen BK, et al. Kvantitativ forskningsmetodologi i samfunnsfag- og helsefag. Bergen: Fagbokforlaget; 2010.

111. World Health Organization. World Alliance for Patient Safety: Forward Programme 2005 Geneva: World Health Organization; 2005 [cited 2013 February]. Available from:

www.who.int/patientsafety/en/brochure final.pdf.

112. Stub T, Salamonsen A, Alræk T. Is it Possible to Distinguish Homeopathic Aggravation from Adverse Effects? A Qualitative Study. Forsch Komplementärmed und Klass Naturheilkd. 2011;19(1):13-9.

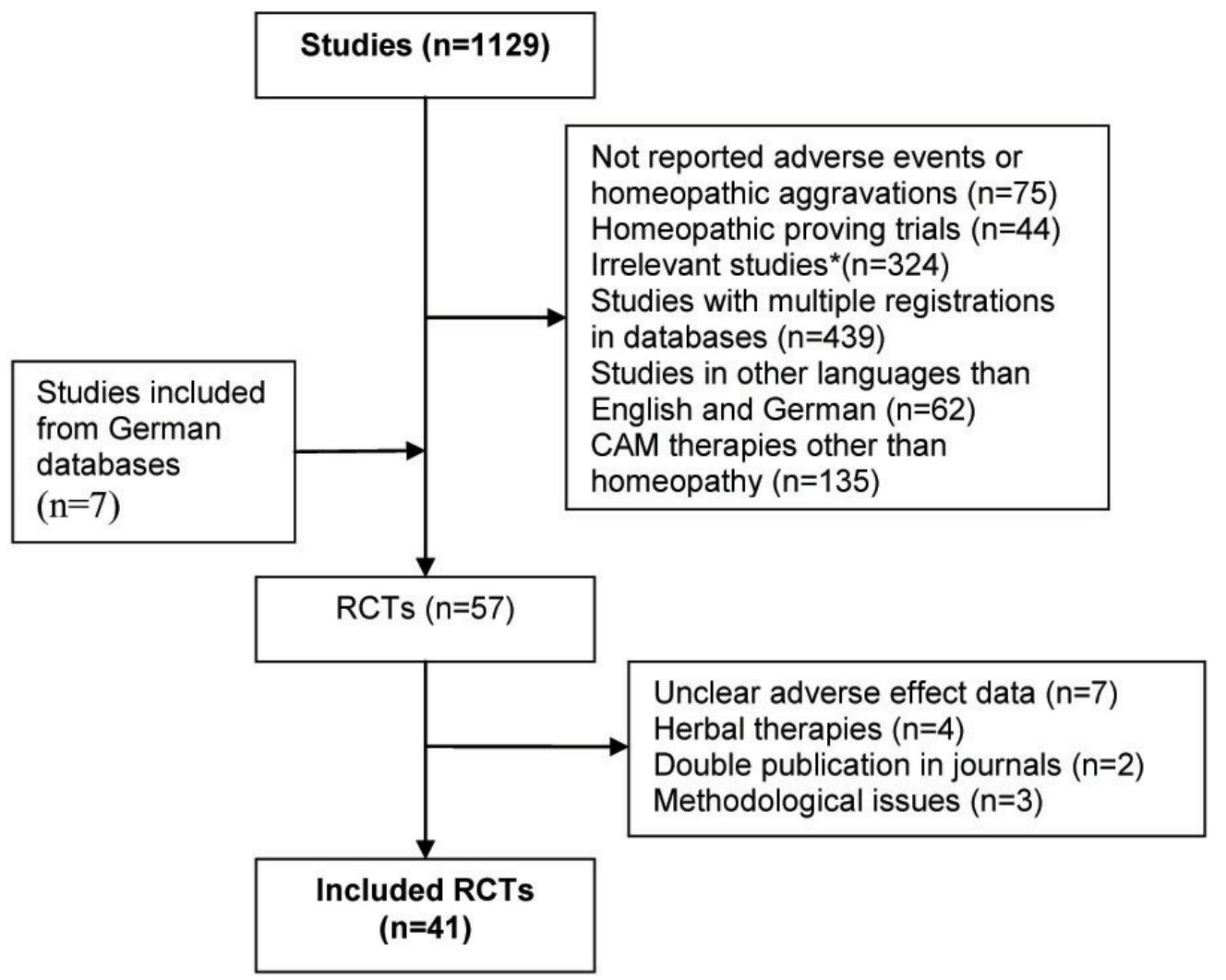

Figure 1. Flow chart for the randomized controlled trials

*Irrelevant studies: Systematic reviews, guidelines, research reviews, cost-benefit evaluations, casereports, letters, comments, debates, self-management and other abstracts 


\begin{tabular}{|c|c|c|c|c|c|c|c|c|c|c|}
\hline \multirow{2}{*}{$\begin{array}{l}\text { Study or Subgroup } \\
\text { 1.1.1 Placebo }\end{array}$} & log[Odds Ratio] & SE & $\begin{array}{r}\text { Homeoapthy } \\
\text { Total }\end{array}$ & Control & Weight & $\begin{array}{c}\text { Odds Ratio } \\
\text { IV, Random, } 95 \% \mathrm{Cl}\end{array}$ & \multicolumn{4}{|c|}{$\begin{array}{c}\text { Odds Ratio } \\
\text { IV, Random, } 95 \% \mathrm{Cl}\end{array}$} \\
\hline & & & & & & & & & & \\
\hline Attena 1995 & 0.7 & 0.12 & 783 & 790 & $5.7 \%$ & $2.01[1.59,2.55]$ & & & $\rightarrow$ & \\
\hline Beer 1999 & 0 & 0.63 & 20 & 20 & $1.1 \%$ & $1.00[0.29,3.44]$ & & & & \\
\hline Bergmann 2000 & 0 & 0.24 & 39 & 39 & $3.9 \%$ & $1.00[0.62,1.60]$ & & & - & \\
\hline Brinkhaus 2006 & 0 & 0.28 & 116 & 113 & $3.4 \%$ & $1.00[0.58,1.73]$ & & & & \\
\hline Cornu 2010 & -0.38 & 0.46 & 46 & 46 & $1.8 \%$ & $0.68[0.28,1.68]$ & & & L & \\
\hline Dieffenbach 1997 & -0.31 & 0.13 & 129 & 129 & $5.6 \%$ & $0.73[0.57,0.95]$ & & $\rightarrow$ & & \\
\hline Frass 2005 & 0 & 0.62 & 35 & 35 & $1.1 \%$ & $1.00[0.30,3.37]$ & & & & \\
\hline Friese 2001 & 0.01 & 0.18 & 50 & 47 & $4.8 \%$ & $1.01[0.71,1.44]$ & & & - & \\
\hline Friese 2007 & 0 & 0.62 & 72 & 72 & $1.1 \%$ & $1.00[0.30,3.37]$ & & & & \\
\hline Jacobs 2001 & 0.04 & 0.62 & 36 & 39 & $1.1 \%$ & $1.04[0.31,3.51]$ & & & & \\
\hline Jacobs 2005 & -0.33 & 0.62 & 56 & 27 & $1.1 \%$ & $0.72[0.21,2.42]$ & & & & \\
\hline Jacobs $2005 a$ & -0.02 & 0.37 & 22 & 21 & $2.4 \%$ & $0.98[0.47,2.02]$ & & & & \\
\hline Jacobs 2007 & 0.03 & 0.62 & 29 & 31 & $1.1 \%$ & $1.03[0.31,3.47]$ & & & & \\
\hline Jeffrey 2002 & -0.07 & 0.75 & 20 & 17 & $0.8 \%$ & $0.93[0.21,4.06]$ & & & & \\
\hline Kim 2005 & -0.48 & 0.39 & 20 & 20 & $2.3 \%$ & $0.62[0.29,1.33]$ & & & & \\
\hline Lewith 2002 & -0.01 & 0.62 & 122 & 120 & $1.1 \%$ & $0.99[0.29,3.34]$ & & & & \\
\hline Mousavi 2009 & 0 & 0.62 & 50 & 50 & $1.1 \%$ & $1.00[0.30,3.37]$ & & & & \\
\hline Naudé2010 & 0.03 & 0.63 & 16 & 17 & $1.1 \%$ & $1.03[0.30,3.54]$ & & & & \\
\hline Oberbaum 2001 & -1.2 & 0.5 & 15 & 15 & $1.6 \%$ & $0.30[0.11,0.80]$ & & & & \\
\hline Oberbaum 2005 & -0.39 & 0.63 & 28 & 12 & $1.1 \%$ & $0.68[0.20,2.33]$ & & & & \\
\hline Paris 2008 & 0.15 & 0.62 & 66 & 92 & $1.1 \%$ & $1.16[0.34,3.92]$ & & & & \\
\hline Silk 2005 & 0.14 & 0.35 & 33 & 33 & $2.6 \%$ & $1.15[0.58,2.28]$ & & & & \\
\hline Singer 2010 & 0.01 & 0.24 & 39 & 40 & $3.9 \%$ & $1.01[0.63,1.62]$ & & & & \\
\hline Steinsbekk 2005 & 0 & 0.62 & 126 & 125 & $1.1 \%$ & $1.00[0.30,3.37]$ & & & & \\
\hline Steinsbekk $2005 a$ & 1.28 & 0.45 & 82 & 87 & $1.9 \%$ & $3.60[1.49,8.69]$ & & & & \\
\hline Stevensen 2003 & -0.07 & 0.34 & 42 & 22 & $2.7 \%$ & $0.93[0.48,1.82]$ & & & & \\
\hline Straumsheim 2000 & -0.04 & 0.23 & 35 & 33 & $4.0 \%$ & $0.96[0.61,1.51]$ & & & & \\
\hline Tayler 2005 & 0.14 & 0.07 & 24 & 27 & $6.4 \%$ & $1.15[1.00,1.32]$ & & & & \\
\hline Thompson 2005 & 0.02 & 0.28 & 28 & 25 & $3.4 \%$ & $1.02[0.59,1.77]$ & & & & \\
\hline Vickers 1998 & -0.13 & 0.2 & 200 & 200 & $4.5 \%$ & $0.88[0.59,1.30]$ & & & & \\
\hline Zabolotnyi 2007 & 0.81 & 0.48 & 57 & 56 & $1.7 \%$ & $2.25[0.88,5.76]$ & & & & \\
\hline Subtotal $(95 \% \mathrm{Cl})$ & & & 2436 & 2400 & $76.7 \%$ & $1.03[0.89,1.20]$ & & & & \\
\hline \multicolumn{11}{|c|}{$\begin{array}{l}\text { Heterogeneity: } \text { Tau }^{2}=0.06 ; \mathrm{Chi}^{2}=58.57, \mathrm{df}=30(\mathrm{P}=0.001) ; \mathrm{I}^{2}=49 \% \\
\text { Test for overall effect: } Z=0.41(P=0.69)\end{array}$} \\
\hline \multicolumn{11}{|l|}{ 1.1.2 Comventional } \\
\hline Stam 2001 & -0.73 & 0.17 & 83 & 78 & $4.9 \%$ & $0.48[0.35,0.67]$ & & & & \\
\hline van Haselen 2000 & -0.16 & 0.18 & 91 & 89 & $4.8 \%$ & $0.85[0.60,1.21]$ & & & & \\
\hline Weiser 1998 & 0.05 & 0.18 & 59 & 60 & $4.8 \%$ & $1.05[0.74,1.50]$ & & & & \\
\hline Weiser 1999 & 0.32 & 0.54 & 72 & 74 & $1.4 \%$ & $1.38[0.48,3.97]$ & & & & \\
\hline Witt 2009 & 0 & 0.54 & 50 & 100 & $1.4 \%$ & $1.00[0.35,2.88]$ & & & & \\
\hline Subtotal $(95 \% \mathrm{Cl})$ & & & 355 & 401 & $17.3 \%$ & $0.82[0.56,1.21]$ & & & & \\
\hline \multicolumn{11}{|c|}{$\begin{array}{l}\text { Heterogeneity: } \operatorname{Tau}^{2}=0.11 ; \mathrm{Chi}^{2}=12.30, \mathrm{df}=4(P=0.02) ; \mathrm{I}^{2}=67 \% \\
\text { Test for overall effect: } Z=1.00(P=0.32)\end{array}$} \\
\hline \multicolumn{11}{|l|}{ 1.1.3 Herbal } \\
\hline Issing 2005 & -0.33 & 0.54 & 87 & 83 & $1.4 \%$ & $0.72[0.25,2.07]$ & & & & \\
\hline Subtotal $(95 \% \mathrm{Cl})$ & & & 87 & 83 & $1.4 \%$ & $0.72[0.25,2.07]$ & & & & \\
\hline \multicolumn{11}{|c|}{$\begin{array}{l}\text { Heterogeneity: Not applicable } \\
\text { Test for overall effect: } Z=0.61(P=0.54)\end{array}$} \\
\hline \multicolumn{11}{|l|}{ 1.1.4 Usual care } \\
\hline Relton 2009 & 0.02 & 0.63 & 23 & 24 & $1.1 \%$ & $1.02[0.30,3.51]$ & & & & \\
\hline \multicolumn{11}{|c|}{ Heterogeneity: Not applicable } \\
\hline \multicolumn{11}{|c|}{ Test for overall effect: $Z=0.03(P=0.97)$} \\
\hline \multicolumn{11}{|c|}{ 1.1.6 Corventional medicine and Placebo } \\
\hline White 2003 & 0.18 & 0.27 & 46 & 47 & $3.5 \%$ & $1.20[0.71,2.03]$ & & & & \\
\hline Subtotal $(95 \% \mathrm{Cl})$ & & & 46 & 47 & $3.5 \%$ & $1.20[0.71,2.03]$ & & & & \\
\hline Heterogeneity: Not ak & plicable & & & & & & & & & \\
\hline Test for overall effect: & $Z=0.67(P=0.50)$ & & & & & & & & & \\
\hline Total $(95 \% \mathrm{Cl})$ & & & 2947 & 2955 & $100.0 \%$ & $0.99[0.86,1.14]$ & & & & \\
\hline $\begin{array}{l}\text { Heterogeneity: } \text { Tau }^{2}= \\
\text { Test for overall effect } \\
\text { Test for subqroup dif }\end{array}$ & $\begin{array}{l}0.08 ; \mathrm{Chi}^{2}=83.29, \\
\mathrm{Z}=0.18(\mathrm{P}=0.86)\end{array}$ & $\begin{array}{l}d f=3 \\
98, d f=\end{array}$ & $\begin{array}{l}38(P=0.0001) ; \\
=4(P=0.74) \cdot I^{2}\end{array}$ & $\begin{array}{l}I^{2}=54 \% \\
=0 \%\end{array}$ & & & $\longmapsto 01$ & $\begin{array}{l}0.1 \\
\text { Homeopathy }\end{array}$ & Control 10 & 100 \\
\hline
\end{tabular}

Figure 2: Forest plot for the randomized controlled trials, including sub-group analysis according to the category of controls 
Table 1: Definitions of concepts

\begin{tabular}{|c|c|c|}
\hline Terminology & Definition & References \\
\hline Risk & $\begin{array}{l}\text { A compound measure of the probability of an event, and } \\
\text { the magnitude and impact of its potentially negative } \\
\text { outcome of that event. }\end{array}$ & $(36),(32)$ \\
\hline Indirect risk & $\begin{array}{l}\text { Risk related to the setting effects, such as the practitioner } \\
\text { rather than to the medicine. For example, a practitioner with } \\
\text { limited medical and homeopathic skills may overlook } \\
\text { serious symptoms and thereby cause a delay in necessary } \\
\text { conventional treatment. }\end{array}$ & (6), (37) \\
\hline Direct risk & $\begin{array}{l}\text { Risk related to the intervention, e.g., harm caused by } \\
\text { pharmacological products, medical treatments and } \\
\text { procedures }\end{array}$ & (5), (6) \\
\hline $\begin{array}{l}\text { Homeopathic } \\
\text { aggravations } \\
\text { (direct and indirect } \\
\text { risk) }\end{array}$ & $\begin{array}{l}\text { A temporary worsening of existing symptoms following the } \\
\text { administration of a correctly chosen homeopathic } \\
\text { prescription, which is expected to be followed by an } \\
\text { improvement. }\end{array}$ & (38), (22) \\
\hline $\begin{array}{l}\text { Adverse effects } \\
\text { (direct and indirect } \\
\text { risk) }\end{array}$ & $\begin{array}{l}\text { All diseases or unwanted and/or harmful reactions resulting } \\
\text { from a medication or an intervention, regardless of their } \\
\text { relation to the actual treatment. }\end{array}$ & (39),(32) \\
\hline $\begin{array}{l}\text { Adverse reactions } \\
\text { (direct and indirect } \\
\text { risk) }\end{array}$ & $\begin{array}{l}\text { Present when the right drug was administered for the } \\
\text { correct indication, in the proper dose, by the right route, yet } \\
\text { still the patient develops an unwanted symptom, suffers } \\
\text { unexpectedly, and is exposed to unpreventable harm. } \\
\text { Adverse reactions may also result from some diagnostic } \\
\text { tests, therapeutic interventions or devices. }\end{array}$ & $(36),(40)$ \\
\hline $\begin{array}{l}\text { Adverse drug } \\
\text { reactions } \\
\text { (direct risk) }\end{array}$ & $\begin{array}{l}\text { An appreciably harmful or unpleasant reaction, resulting } \\
\text { from an intervention related to the use of a medicinal } \\
\text { product. The reaction predicts hazards regarding future } \\
\text { administration and warrant prevention or specific treatment, } \\
\text { or alteration of the dosage regimen, or withdrawal of the } \\
\text { product. }\end{array}$ & $(32,41)$ \\
\hline
\end{tabular}


Table 2: Excluded studies

Table 2: Excluded studies

\begin{tabular}{|c|c|c|}
\hline Study id & Method & Reason for exclusion \\
\hline Aabel, 2010 & RCT & $\begin{array}{l}\text { On a general level, discussed whether a prophylactic treatment } \\
\text { schedule could minimize the problems of HA in homeopathy. No } \\
\text { AE/HA data }\end{array}$ \\
\hline Bell, 2004 & RCT & No $A E / H A$ data \\
\hline Bell, 2004 & RCT & No AE/HA data \\
\hline Bernstein, 2006 & RCT & Active medication was a herbal ointment \\
\hline Ferrera, 2008 & RCT & Active medication was not homeopathic medication \\
\hline Frass, 2011 & RCT & Double publication \\
\hline Friese 1997 & RCT & Double publication (Friese 2001) \\
\hline Garrett, 1997 & RCT & Unclear randomization process \\
\hline Hill, 1996 & RCT & Active medication was a herbal product (mother tincture) \\
\hline Jeaner, 2000 & RCT & Data on "secondary effects", which was not defined \\
\hline Katz, 2005 & RCT & No results available, due to low compliance \\
\hline Mousavi, 2009 & RCT & $\begin{array}{l}\text { Suggested that the verum (Ignatia) was a potentially low risk } \\
\text { option in treating lichten planus, without reporting AE/ HA }\end{array}$ \\
\hline Schirmer, 2000 & RCT & $\begin{array}{l}\text { Not a homeopathic intervention. Reinjection of patient's own } \\
\text { blood ("Eigenblut") }\end{array}$ \\
\hline Seeley, 2006 & RCT & $\begin{array}{l}\text { The study reported no complications after face lifts, no AE/HA } \\
\text { data from homeopathic treatment }\end{array}$ \\
\hline Strösser, 2000 & RCT & No AE/HA data \\
\hline Tveiten, 2003 & RCT & Pooled data from two studies \\
\hline \multicolumn{3}{|c|}{$\begin{array}{l}\text { AE: Adverse effects } \\
\text { HA: Homeopathic aggravations }\end{array}$} \\
\hline
\end{tabular}




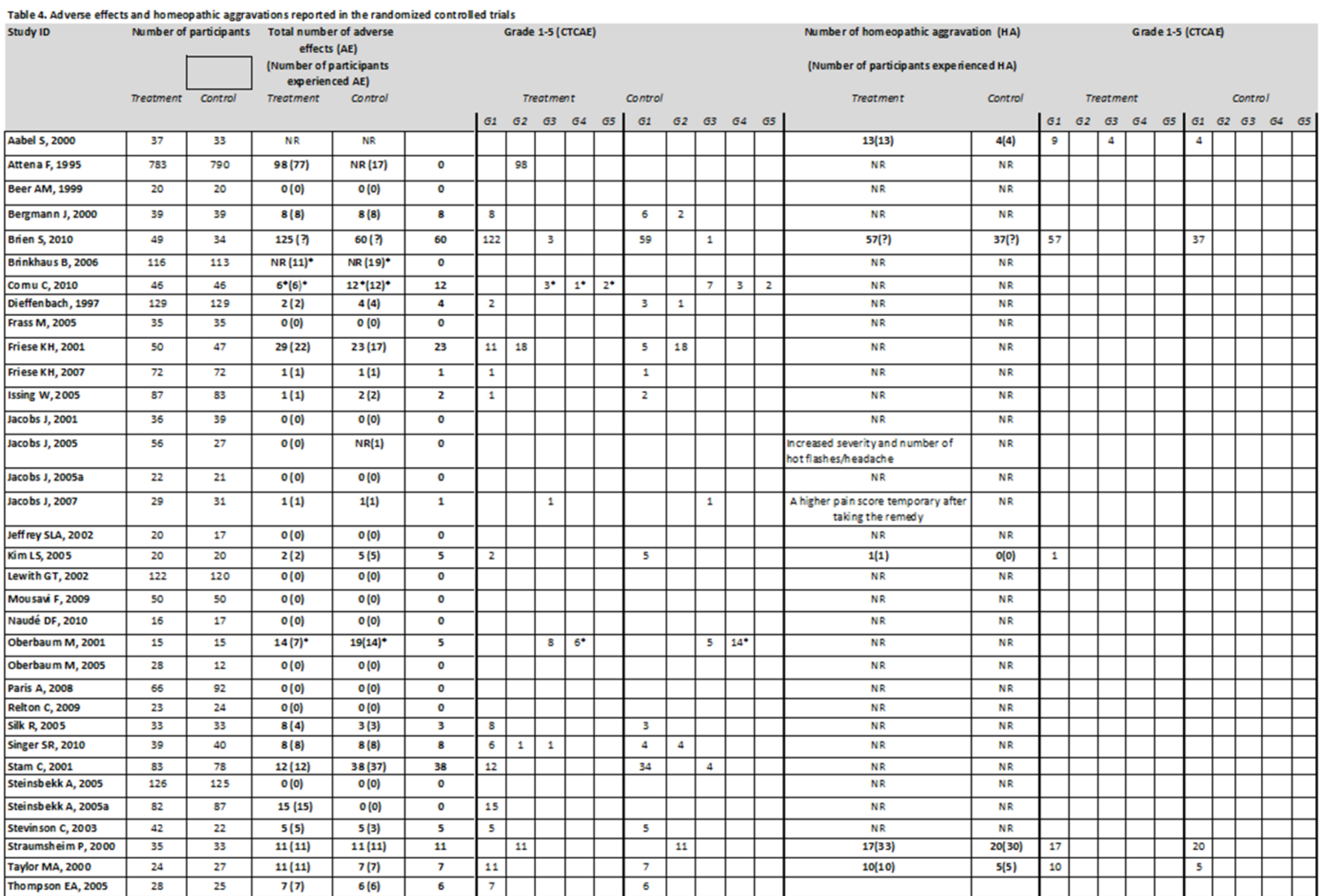




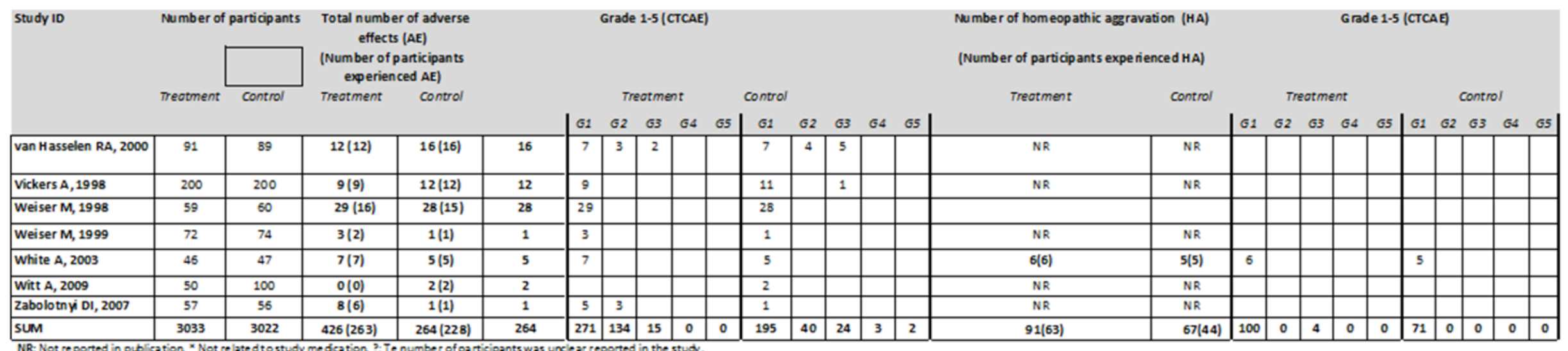

NR: Not reported in pubication * Not re bted tostudy medcation 2: Te number of participants was unclear reported in the stud. 


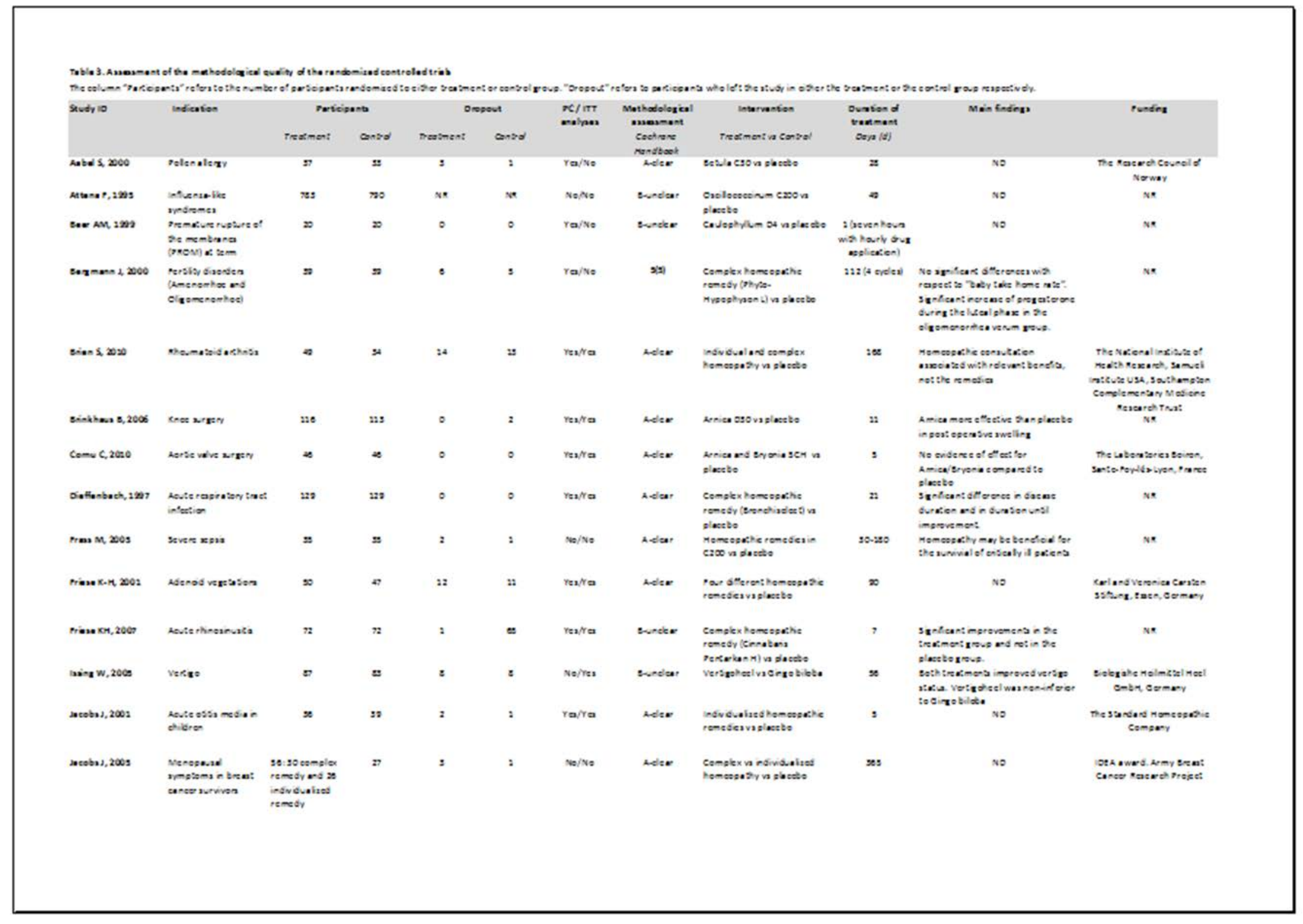




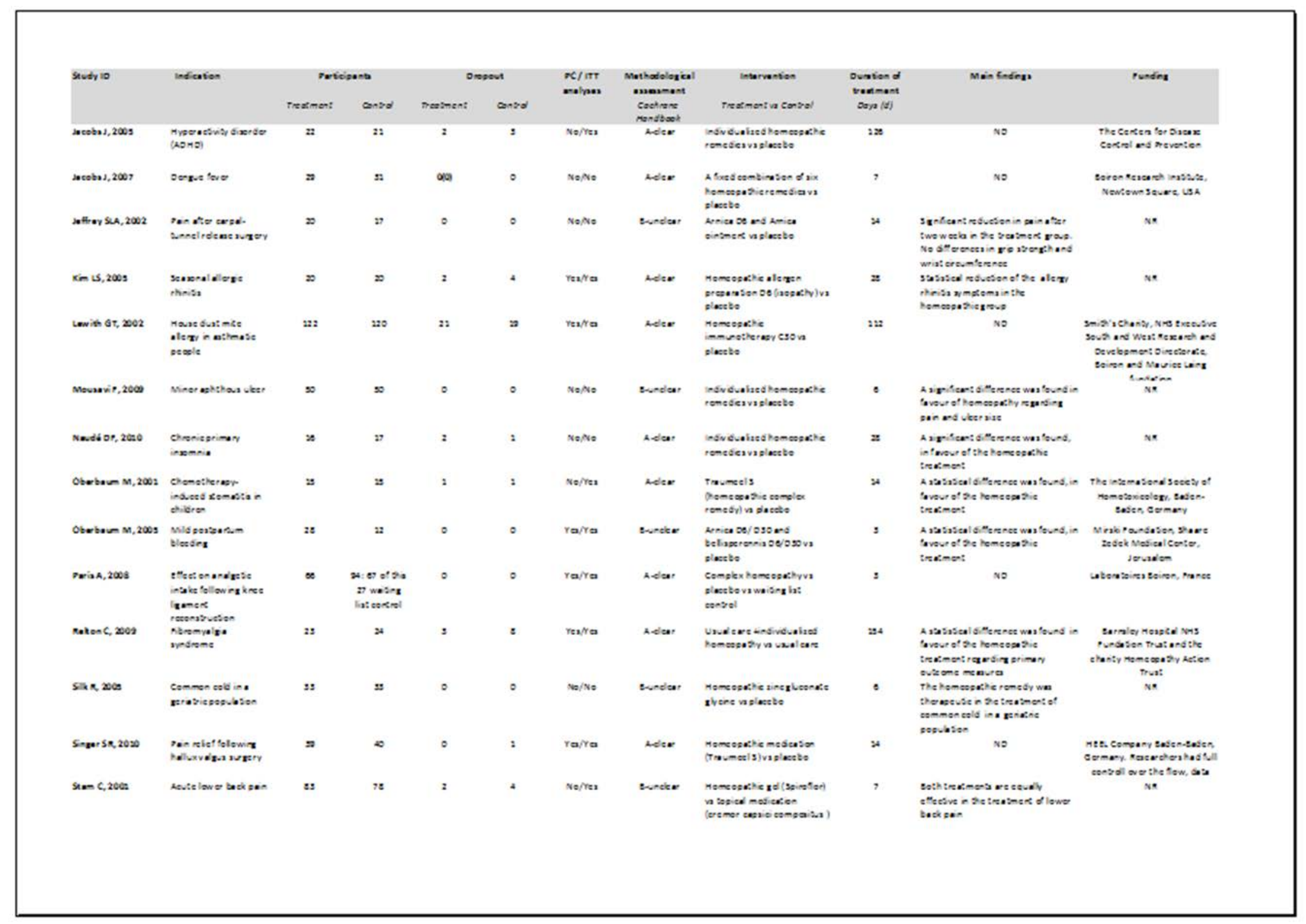




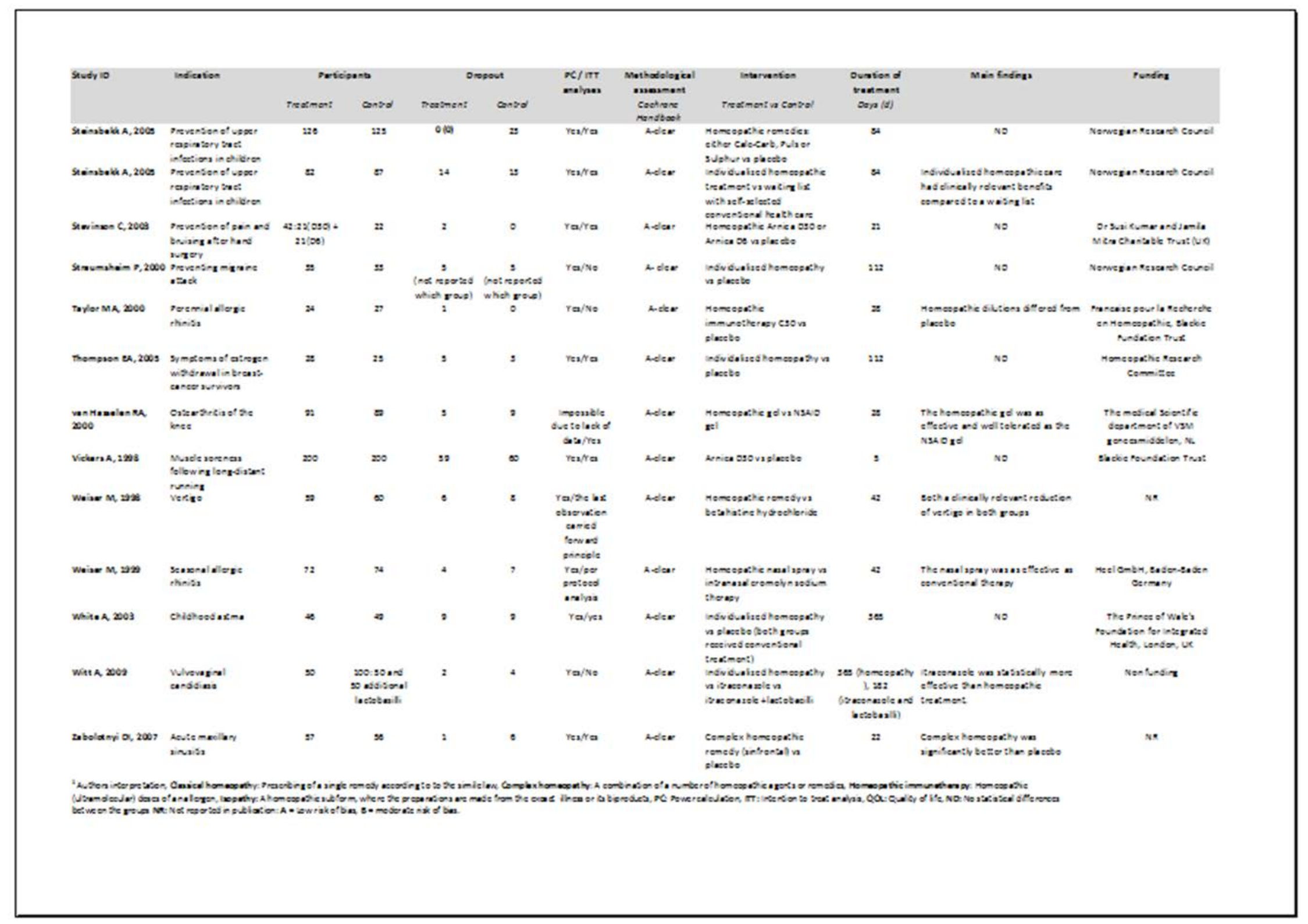




\section{Additional information}

\section{Search Results}

\section{Show results in:}

Cochrane Reviews [0] Other Reviews [0] Trials [30] Methods Studies [0] Technology Assessments [0] Economic Evaluations [0] Cochrane groups [0]

There are $\mathbf{3 0}$ results out of $\mathbf{6 7 0 1 5 4}$ records for “(\#4 AND \#9) in Cochrane central Register of Controlled Trials"

\section{Cochrane Library}

\begin{tabular}{|c|c|c|c|c|}
\hline ID & Search & Hits & Edit & Delete \\
\hline$\# 1$ & (homeopathy) ti.ab,kw or (homoeopathy) ti.ab, kw or (homeopathic)tiab, kw or (homoeopathic) tiab, kw & 545 & edr & delete \\
\hline$\approx 2$ & MeSH descriotor Homeopathy explode tree 1 & 202 & edt & delete \\
\hline$\approx 3$ & $(\# 10 R \approx 2)$ & 545 & edis & delete \\
\hline$=4$ & $(E 10 R=2)$ from 1995 to 2001 & 199 & edf & delete \\
\hline$=5$ & (aoeravation"), tiab, kw or (homeopathic aegravation") ti. ab, kw & 293 & edr & delete \\
\hline$\approx 6$ &  & 164129 & edis & delete \\
\hline$\approx 7$ & MeSH descriptor Druq Toxicity explode all trees & 1259 & edit & delete \\
\hline$\approx 8$ & MeSH descriotor Safety explode all trees & 2950 & edit & delete \\
\hline$=9$ & $(\approx S O R=6 \quad O R=7 O R \approx 8)$, from 1995 to 2001 & 40429 & edr & delete \\
\hline$=10$ & $(\# 4$ AND $\approx 9)$ & 31 & edt & delete \\
\hline
\end{tabular}

Save Search Strategy Clear History 
Wiley InterScience: Cochrane Search History

Advanced Search | MeSH Search | Search History | Saved Searches

Search For:

Restrict by product:

Ctrl-click (Windows) or

Command-click (Mac)

to select
All Cochrane products (default)

Cochrane Reviews

Other Reviews

Clinical Trials

Restrict by record status:

$\checkmark$ All

$\begin{array}{lll}\square \text { New } & \square \text { Conclusions Changed } & \square \text { Commented } \\ \square \text { New Search } & \square \text { Major Change } & \square \text { Withdrawn }\end{array}$

Commented

(Choose one or more specific statuses above and use this option to limit these selections to commented articles.)

Date Range (4-digit year):

homeopathic aggravation:

03.09.2010

ID Search

\#1 (homeopathic):ti.ab,kw or (homoeonathic):ti.ab.kw or (homeopathv):tiab, kw or (homoeopathv):ti.ab, kw

\#2 MeSH descriptor Homeopathy explode tree 1

\#3 (\#1 OR\#2)

\#4 (\#1 OR \#2), from 2002 to 2010

\#5 (agaravation*):tiab. kw or (homeonathic agaravation *) ti

\#6 (adverse effect*):tiab.kw or (safetv):ti,ab.kw or (adverse event*):ti.ab,kw or (side effect"):ab

\#7 MeSH descriptor Drug Toxicity explode all trees

\#8 (\#5 OR \#6 OR \#7) from 2002 to 2010

\#9 (\#3 AND \#8) from 2002 to 2010
Hits Edit Delete

523 edit delete

194 edit delete

523 edit delete

129 edit delete

276 edit delete

150487 edit delete

1120 edit delete

54135 edit delete

35 edit delete

Save Sarch Strategy

Clear Hislory 
PubMed Advanced Search

Search Builder

\begin{tabular}{l|l}
\hline All Fields & AND
\end{tabular}

Add to Search Box

Show Index

Search Builderinstnuctions

\begin{tabular}{|c|c|c|c|}
\hline Search & Most Recent Queries & Time & Result \\
\hline 苂 & Search (\#11) AND \#16 Limits: Humans, Clinical Trial, Randomized Controlled Trial, English, published in the last 10 years & $09: 52: 29$ & 16 \\
\hline$\# 16$ & $\begin{array}{l}\text { Search ((\#12) OR \#13) OR \#15 Limits: Humans, Clinical Trial, Randomized Controlled Trial, English, published in the last } 10 \\
\text { years }\end{array}$ & $09: 51: 45$ & 35380 \\
\hline H15 & $\begin{array}{l}\text { Search ("Risk Management"[Mesh] OR "Drug Tolerance"[Mesh]) Limits: Humans, Clinical Trial, Randomized Controlled Trial, } \\
\text { English, published in the last } 10 \text { years }\end{array}$ & $09: 50: 44$ & 8197 \\
\hline \#13 & $\begin{array}{l}\text { Search (((adverse effect[Titie/Abstract)] OR adverse event(Title/Abstract]) OR side effect[Titie/Abstract)) OR safety } \\
\text { [Titie/Abstract] Limits: Humans, Clinical Trial, Randomized Controlled Trial, English, published in the last } 10 \text { years }\end{array}$ & $09: 49: 36$ & 28129 \\
\hline & $\begin{array}{l}\text { Search (aggravation[Title/Abstract]) OR homeopathic aggravation[Title/Abstract] Limits: Humans, Clinical Trial, Randomized } \\
\text { Controlled Trial, English, published in the last } 10 \text { years }\end{array}$ & 09:48:39 & 108 \\
\hline t111 & Search (\$7) OR $\# 9$ Limits: Humans, Clinical Trial, Randomized Controlled Trial, English, published in the last 10 years & $09.43: 54$ & 146 \\
\hline I99s & $\begin{array}{l}\text { Search ("Homeopathy"[Mesh] OR "Materia Medica"[Mesh]) Limits: Humans, Clinical Trial, Randomized Controlled Trial, English, } \\
\text { published in the last } 10 \text { years }\end{array}$ & $09: 39.18$ & 118 \\
\hline \#\# & $\begin{array}{l}\text { Search (homeopathy[Title/Abstract]) OR homeopathic[Title/Abstract] Limits: Humans, Clinical Trial, Randomized Controlled } \\
\text { Trial, English, published in the last } 10 \text { years }\end{array}$ & $09: 37: 22$ & 127 \\
\hline
\end{tabular}

Less History Clear History

Search History instructions 